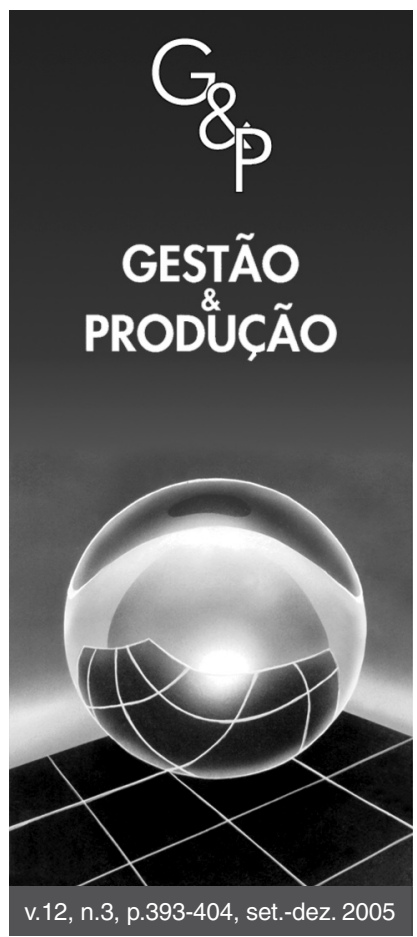

\title{
ESTRATÉGIA DE RELACIONAMENTO ENTRE OS MEMBROS DA CADEIA PRODUTIVA NO BRASIL: REFLEXÕES SOBRE O TEMA
}

\author{
Maria Celeste Reis Lobo Vasconcelos \\ Fundação Pedro Leopoldo, \\ Rua Teófilo Calazans de Barros, 100, C. P. 123, \\ CEP 33600-000, Pedro Leopoldo, MG, \\ e-mail: celestevasconcelos@terra.com.br \\ Rosileia Milagres \\ Edna do Nascimento \\ Fundação Dom Cabral, \\ Av. Princesa Diana, 760, Alphaville, CEP 34000-000, Nova Lima, MG, \\ e-mail: rosileiam@fdc.org.br, edna@fdc.org.br
}

Resumo

Recebido em 04/7/2005

Aceito em 21/9/2005

O crescente número de alianças entre as organizações tem propiciado a formação de verdadeiras redes, configurando o que se chama hoje de Sociedade em Rede. Observa-se que a maior parte do valor dos produtos das empresas é produzida nestas redes e não mais isoladamente por uma única empresa. O presente artigo tem por objetivo discutir a estratégia de relacionamento entre os membros da cadeia produtiva no Brasil, com foco na aprendizagem e no compartilhamento do conhecimento, em contextos marcados pela inovação e pela formação de redes. São apresentados os resultados parciais de uma pesquisa em cadeias produtivas no Brasil, envolvendo 46 empresas. São analisados os relacionamentos das empresas com fornecedores, distribuidores, clientes e consumidores finais. Os resultados da pesquisa são comparados com um caso de sucesso de cadeia produtiva do setor automobilístico, descrito na literatura. Os resultados mostram que existe ainda um longo percurso a ser perseguido pela maioria das empresas para se inserirem na chamada Sociedade em Rede.

Palavras-chave: estratégia, sociedade em rede, cadeia produtiva, aprendizagem, conhecimento, inovação.

\section{Introdução}

As redes se tornaram importantes variáveis estratégicas para as empresas, afetaram toda a estrutura empresarial e a forma de competição. Observa-se, hoje, que a maior parte do valor dos produtos das empresas é produzida nestas redes e não mais isoladamente por uma única empresa. A partir disto, recursos críticos para a competitividade da empresa, como o conhecimento, deve ser compartilhado, explorado e aplicado numa perspectiva de rede. Estas redes podem ser vistas como entidades formadas por uma diversidade de conhecimentos e competências críticas e fundamentais para as empresas participantes, o que confere a elas uma capacidade competitiva de adquirir, armazenar e renovar conhecimentos tácitos de uma forma muito mais dinâmica. Assim, para explorar o máximo da capacidade competitiva da rede, as empresas devem ser capazes de instituir rotinas (processos) que levem à cria- ção de uma forte identidade de rede e que possibilitem o acesso rápido e fácil dos participantes ao conhecimento tácito produzido na rede. Desta forma, todos os participantes se beneficiam não só dos resultados comuns, mas também dos resultados específicos. Observa-se que a forma de interação entre as empresas na sociedade em rede constitui, hoje, um tema central para inúmeras pesquisas que procuram captar a sofisticação das relações entre elas e caracterizar a dinâmica competitiva da atualidade.

Com base neste novo ambiente marcado pela busca do conhecimento coletivo, o presente artigo tem por objetivo discutir a estratégia de relacionamento entre os membros da cadeia produtiva no Brasil, com foco na aprendizagem e no compartilhamento do conhecimento em contextos marcados pela formação de redes. São apresentados os resultados de uma pesquisa sobre cadeias produtivas com 
46 empresas no Brasil em que são analisados os relacionamentos das empresas com fornecedores, distribuidores, clientes e consumidores finais. São apresentados os conceitos centrais que sustentam a discussão, como a importância do conhecimento, do aprendizado e da inovação na sociedade em rede e os impactos destes conceitos no pensamento e na formulação estratégica. Finalmente, os resultados da pesquisa são comparados com um caso de sucesso de cadeia produtiva do setor automobilístico, descrito na literatura.

\section{As empresas na sociedade em rede}

$\mathrm{Na}$ economia do aprendizado, o conhecimento é um ativo fundamental para o sucesso no processo competitivo, mas sua utilização, enquanto recurso estratégico, impõe às empresas a busca por novas formas de organização e interação entre si e os demais agentes - fornecedores, consumidores, distribuidores, clientes, instituições de pesquisa, governo, comunidade, etc. Uma importante expressão destas novas configurações é a formação de redes de longo prazo entre os parceiros de negócios. Vários estudos têm mostrado a importância de se otimizar o conhecimento e a aprendizagem interativa, proveniente, em geral, de competências distribuídas entre os diferentes participantes das redes. Segundo Lundvall (1992):

"estamos nos movendo em direção de uma sociedade em rede onde a oportunidade e capacidade de ter acesso e participar de redes intensivas em conhecimento - e aprendizagem - determinam a posição sócio econômica dos indivíduos e das firmas. A economia está se transformando numa hierarquia de redes com algumas redes globais no topo e uma crescente proporção de excluídos sociais na base da pirâmide (p. 34)".

Esta estrutura em rede criou uma grande complexidade nos ambientes internos e externos das organizações e uma pressão que é sentida, principalmente, na área de formação de estratégia. Este tema representa hoje um assunto central para inúmeras pesquisas que procuram captar a sofisticação das relações entre as empresas e caracterizar a dinâmica competitiva das cadeias produtivas na atualidade.

\subsection{A inovação e a estratégia na sociedade em rede}

Os processos de transformação que têm agitado as economias nos últimos anos têm, por aspecto mais significativo, a importância dada às inovações. A tecnologia ocupou papéis centrais, tendo por foco o aumento da eficiência do sistema produtivo. Foram priorizados os sistemas de fabricação flexíveis, que podem atender à necessidade de personalização e diversificação da produção. Em termos de organização do trabalho, foi priorizada também a flexibilização da mão-de-obra, o que permite ajustes rápidos às mudanças realizadas nos mercados. $\mathrm{A}$ competição tornou-se global. Esta busca constante por inovação, no entanto, já no início do século passado, era percebida como elemento chave para o desenvolvimento (Schumpeter, 1984). As inovações ocupam, portanto, no cenário atual, um papel de destaque. Podem estar na origem de baixos custos, aumentos na produtividade, melhoria na qualidade dos produtos e/ou diferenciação, agregação de serviços, adequação às necessidades dos clientes, etc. As inovações podem rejuvenescer setores, abrir novos negócios, assim como tornar negócios anteriormente rentáveis em negócios obsoletos; isto é, possuem a capacidade de transformar o ambiente econômico, mudar os parâmetros da concorrência, mudar as escolhas estratégicas das organizações. Por possuírem as capacidades citadas, as inovações são frutos dos desejos dos capitalistas. No entanto, a introdução de inovações não pode ser entendida como um processo simples. Ao contrário, ela exige perspicácia empresarial, exige um desenho organizacional que permita à organização perceber oportunidades de mercado e usar seus recursos de maneira adequada, exige um processo contínuo que envolve aprender e "desaprender", dentre outros elementos que podem ser considerados no âmbito da empresa (Vasconcelos, 2000).

O fato da competitividade das empresas no mundo globalizado depender da inovação de produtos e processos e de um esforço de P\&D tem representado um grande desafio para os dirigentes das empresas. Segundo Leonard Barton (1998), estes gerentes precisam expor suas empresas a um bombardeio de novas idéias vindas de fora, a fim de combater as limitações estratégicas e incentivar os empregados a coletarem e disseminarem informações internamente. Além disto, a empresa precisa desenvolver uma rede de conhecimento, formando um ambiente propício à inovação. Na realidade, pode-se considerar que a inovação e a estratégia são faces da mesma moeda e estão sempre interligadas no ambiente empresarial. O impacto da competição acirrada tem forçado as organizações a buscarem maior capacidade de resposta às demandas individualizadas e em contínua mudança dos clientes (do mercado). Como conseqüência, as ações estratégicas devem ser decididas de novas maneiras, envolvendo agilidade para aproveitar as oportunidades. Algumas destas oportunidades estão sendo aproveitadas e viabilizadas pelo estabelecimento de parcerias e tem propiciado a formação de verdadeiras redes, como redes de valor, redes de conhecimento, redes de suprimento, configurando o que se chama hoje de Sociedade em Rede.

\subsection{Aprendizagem e compartilhamento do conhecimento na sociedade em rede}

Para Kale et al. (2000), os estudos sobre redes estão tendendo para a questão do aprendizado. A possibilidade 
de acessar ou adquirir informações críticas, know-how ou capacitações do parceiro são freqüentemente citadas como sendo as maiores motivações para a formação de redes. Estas redes são vistas, não somente como um meio de negociar acesso às capacitações complementares do outro, mas também como um mecanismo para adquirir ou internalizar as técnicas e habilidades do parceiro. Os autores ressaltam que alianças com o objetivo de aprendizagem constituem uma importante classe de aliança. As empresas enfrentam o desafio de gerenciar o equilíbrio entre aprender e proteger os seus conhecimentos estratégicos. Yoshino e Rangan (1996) afirmam que tal aprendizado é sempre um objetivo estratégico implícito para cada firma que participa de redes. Como consequiência deste novo arranjo organizacional, Gulati et al. (2000) ressaltam que as empresas que competem por lucros, umas contra as outras em um mercado impessoal, mostram comportamentos crescentemente inadequados em um mundo em que as empresas em redes fortalecem os relacionamentos social, profissional e de trocas com outros atores organizacionais. Tais redes englobam o conjunto, tanto horizontal como vertical, de relacionamentos de uma empresa com outras organizações - sejam eles fornecedores, clientes, competidores, ou outras entidades - incluindo relações entre indústrias e países. Estas redes estão compostas de laços duradouros, de significado estratégico para as empresas que entram nelas e incluem alianças estratégicas, empreendimentos conjuntos e parcerias de comprador-fornecedor de longo prazo. Segundo Gulati et al. (2000), as redes fornecem às empresas informações, recursos, acesso a outros mercados e a outras tecnologias, favorecem o aprendizado e podem gerar economias de escala e de escopo, dentre outros. Um exemplo, citado por estes autores é a indústria automobilística, na qual as mudanças atuais incluem redes com poucos fornecedores, relacionamentos de longo prazo e um maior envolvimento do fornecedor no processo de design. Todos os participantes destas redes têm contribuído significativamente para melhorar a competitividade dos produtores automotivos.

Dyer e Nobeoka (2000) afirmam que a capacidade de aprendizagem de uma empresa vai além da sua capacidade como entidade única, isolada, necessitando para tanto da análise da rede na qual a empresa está inserida. Eles argumentam que estas redes podem ser meios eficazes de aprendizagem interorganizacional em que os clientes e fornecedores podem vir a ser fontes primárias de inovação. Além disto, a empresa deve ser capaz de criar e se posicionar nestas redes de aprendizagem como elemento aglutinador e coordenador, pela criação de rotinas institucionalizadas para o compartilhamento de conhecimento entre os membros participantes. Como fator competitivo sustentável, uma rede pode ser difundida e entendida, mas é de difícil reprodução, pois sua composição e con- figuração conferem-lhe uma identidade única enquanto unidade competitiva.

Dyer e Nobeoka (2000) definem as rotinas de aprendizagem como um padrão regular de interações entre os indivíduos que permitem a transferência, recombinação ou criação de conhecimento especializado. Coletivamente, estas rotinas podem ser vistas como a capacidade da rede de gerenciar os fluxos de conhecimento tácito, que são conhecimentos complexos e de difícil transferência e codificação, entre os elementos da rede. A rede deve ser capaz de criar uma forte identidade de rede, com regras de entrada e participação, em que a produção de conhecimento é vista como propriedade da rede e, portanto, compartilhada por todos os membros. Agindo desta forma, a rede como um todo terá acesso a uma diversidade muito maior de conhecimento, a um custo muito mais baixo que uma empresa sozinha. Segundo estes autores, a Toyota criou uma rede de fornecedores efetiva no compartilhamento de conhecimento, em parte por causa da forte identidade de rede e por causa das normas de rede que dão suporte à coordenação, comunicação e aprendizagem.

Apesar dos riscos relacionados a uma rede com acesso aos conhecimentos tácitos, Dyer (1996) afirma que a confiança entre os componentes da rede é um ativo intangível e ao mesmo tempo um fator competitivo difícil de ser imitado. A confiança cria uma interdependência única entre os elementos da rede à medida que investimentos são feitos na construção dos relacionamentos, no desenvolvimento dos ativos especializados e na própria construção da configuração física da rede. Kale et al. (2000) também chamam a atenção para a importância do capital relacional (ou capital social) que se refere ao nível de confiança mútua, respeito e amizade que cresce nas interações próximas entre os parceiros. Em pesquisa realizada com 592 empresas, os autores mostraram que o capital relacional ajuda as empresas a terem um equilíbrio entre aquisição de novas capacitações com a proteção dos seus patrimônios centrais. Foi demonstrado na pesquisa que, quanto maior o capital relacional existente entre os parceiros da aliança, maior é o grau de aprendizagem dos participantes.

Dyer (1996) argumenta que empresas que participam de redes podem levar vantagem em relação às empresas independentes porque seus parceiros podem fornecerlhes recursos e informações que podem responder efetivamente a choques exógenos. Assim, ele enfatiza que o valor adicionado da empresa vem da conversão dos seus ativos genéricos (capital, matéria-prima, competências gerais, etc.) para ativos especializados (tecnologia, competências centrais, processos especializados, etc.) e que estes ativos especializados podem ser produtos da relação da empresa com os seus parceiros de negócios. Singh e Mitchell (1996) afirmam que os recursos críticos de uma 
empresa podem levá-la à expansão das suas fronteiras e podem surgir de rotinas específicas de colaboração entre empresas que incluem inovação de produto e processo, expansão geográfica, extensão da linha de produção e entrada do produto no mercado. Os autores concordam que o relacionamento cooperativo, além de dar acesso ao conhecimento dominado pelo parceiro, permite que a empresa ainda mantenha e melhore suas habilidades centrais.

Com base na discussão anterior, conclui-se que redes são muito mais que relacionamentos que governam a difusão de inovações e normas, ou que explicam a variabilidade de acesso à informação por empresas concorrentes. As redes constituem capacidades que aumentam o valor das empresas. As redes precisam ser entendidas como sendo fluxos de conhecimento que atravessam as empresas e que o compartilhamento do conhecimento aumenta a capacidade de inovação das empresas participantes.

São apresentados a seguir os resultados de uma pesquisa sobre competitividade da cadeia produtiva no Brasil, com o objetivo de analisar a estratégia de relacionamento entre os parceiros e discutir a importância do compartilhamento do conhecimento em contextos marcados pela formação de redes.

\section{Pesquisa de campo: relacionamento na cadeia produtiva no Brasil}

Participaram da pesquisa as empresas pertencentes à lista das 1000 maiores empresas citadas pela revista Valor Econômico. Neste artigo, é analisado o tipo de estratégia de relacionamento das empresas com fornecedores, distribuidores, clientes e consumidores finais, com foco na aprendizagem e no compartilhamento do conhecimento. Buscou-se, no artigo, avaliar a cadeia produtiva à luz das contribuições mais recentes sobre a natureza do conhecimento, da aprendizagem, da inovação e da estratégia de relacionamentos entre os parceiros, numa sociedade em rede. A coleta de dados foi feita por meio de questionário e as informações foram enviadas pela Internet. As questões analisadas neste artigo foram:

a) estratégia de relacionamento atual das empresas e aquele previsto para daqui a cinco anos com os participantes da cadeia produtiva; e

b) indicadores para a aferição do sucesso da estratégia de relacionamento e grau de utilização dos indicadores.

As perguntas analisadas têm por objetivo revelar a natureza deste relacionamento - se marcado por cooperação, incluindo a prática do compartilhamento do conhecimento, característico das redes competitivas descritas na literatura, ou por relações de mercado. Foram também incluídas perguntas relativas à estratégia de relacionamento daqui a 5 anos. Estas perguntas tiveram por objetivo avaliar se consta das intenções da empresa modificar seu relacionamento com os participantes da cadeia produtiva.

Os questionários, padronizados e estruturados, foram respondidos pela Internet pelo principal executivo e responsável pela estratégia da empresa. A maioria das perguntas dos questionários era de respostas múltiplas, isto é, uma pergunta pode ter mais de uma resposta. A amostra não é aleatória e nem representativa do universo de interesse, ou seja, as mil maiores empresas do Brasil, pois foram enviados questionários para todas as empresas e apenas 46 responderam. Assim, os resultados e conclusões apresentados neste trabalho limitam-se às empresas que compõem a amostra, não podendo, portanto, serem estendidos para as mil maiores empresas do Brasil. Os elementos da cadeia produtiva considerados no questionário foram os fornecedores, distribuidores, clientes e consumidores finais.

\subsection{Caracterização das empresas que constituem a amostra analisada}

A amostra é constituída de 46 empresas, pertencentes à lista das mil maiores empresas do Brasil, segundo a revista Valor Econômico, edição 2003. Estas empresas têm receita líquida anual na faixa de 130 a 19000 milhões de reais, conforme mostrado na Figura 1.

A amostra é composta por 26 empresas do setor industrial, 14 do setor de serviços, 4 do comércio e 2 empresas do setor agrícola. Cerca de 80\% (36 empresas) são de capital nacional - controladas por pessoas físicas e jurídicas brasileiras. O restante (10 empresas) é composto por empresas de capital estrangeiro. A maioria dessas empresas - 64,4\% - possui ações negociadas na bolsa de valores. Outra informação obtida pelo questionário foi que $90 \%$ das empresas consideradas nesta pesquisa avaliam sua estratégia anualmente, e apenas $10 \%$ avaliam de dois em dois anos. Este comportamento pode ser explicado pelo contexto marcado por profundas transformações e grande velocidade de mudanças no padrão de concorrência, exigindo uma revisão cada vez mais frequiente da estratégia.

\subsection{Sofisticação das estratégias de relacio- namento}

Devido às limitações do tamanho da amostra, utilizou-se como fator de análise o nível de sofisticação dos

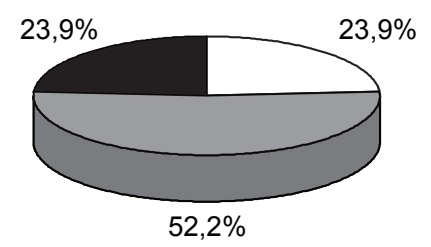

132,30 a 205,82

205,83 a 1424,88

1424,89 a 19131,50

Figura 1. Receita líquida em milhões de reais. Fonte: dados da pesquisa. 
relacionamentos na cadeia produtiva em vez de fatores clássicos como tamanho da empresa e setor ao qual ela pertence. Este fator de análise, criado a partir da literatura sobre a sociedade em rede e sociedade do conhecimento, era representado no questionário pelas perguntas:

- "Indique a alternativa que melhor reflete a atual estratégia da sua empresa em relação aos seus fornecedores"; e

- "Indique a estratégia que deverá predominar daqui a 5 anos".

Estas duas perguntas também foram feitas para os distribuidores, clientes e consumidores finais. A partir disto, as estratégias de relacionamento com os elementos da cadeia foram classificadas como menos sofisticadas ou mais sofisticadas (Tabela 1).

\subsection{Relacionamento com fornecedores}

Quanto ao tipo de relacionamento atual com os principais fornecedores, a amostra concentrou-se na alternativa: "Obter os melhores preços, qualidade e condições de fornecimento", com 73,3\% das respostas. Este resultado mostra que a maioria das empresas pratica hoje estratégias menos sofisticadas (Figura 2).

Este comportamento, no entanto, tende a se alterar no futuro, pois $66,7 \%$ pretendem adotar estratégias mais sofisticadas, em contraposição a 33,3\% que optam por praticar relações menos sofisticadas. A estratégia futura de relacionamento com os fornecedores, envolve a alter- nativa: "Desenvolver ações cooperativas com fornecedores, visando à melhoria geral da cadeia produtiva. Por exemplo: treinamentos conjuntos, certificação de qualidade, assistência técnica, desenvolvimento conjunto de produtos e investimentos em ativos compartilhados".

Embora a estratégia atual adotada pelas empresas não se encontre em consonância com a teoria, a qual sinaliza que, na sociedade do conhecimento, as empresas deveriam buscar relacionamentos de confiança em rede, já existe a percepção da importância das relações de rede, uma vez que as empresas encontram-se compelidas a encaminhar no futuro para este estágio.

A despeito da limitação da amostra que impossibilitou um corte setorial, ressalta-se a baixa importância dada ao relacionamento com os fornecedores pelos respondentes.

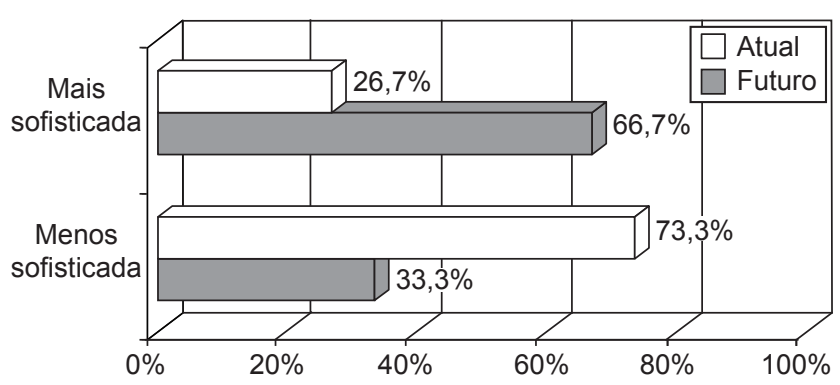

Figura 2. Estratégia de relacionamento com os fornecedores. Fonte: resultados da pesquisa.

Tabela 1. Fator de análise da estratégia de relacionamento na cadeia produtiva.

\begin{tabular}{|c|c|c|}
\hline \multirow{2}{*}{$\begin{array}{c}\text { Elemento da } \\
\text { Cadeia Produtiva }\end{array}$} & \multicolumn{2}{|c|}{ Estratégia Atual de Relacionamento } \\
\hline & Menos Sofisticada & Mais Sofisticada \\
\hline Fornecedor & $\begin{array}{l}\text { 1. Obter os melhores preços, qualidade e } \\
\text { condições de fornecimento. } \\
\text { 2. Estabelecer maior colaboração e comuni- } \\
\text { cação com fornecedores, visando facilitar } \\
\text { o andamento das transações e fluxo de } \\
\text { mercadorias a fim de produzir o maior valor } \\
\text { em conjunto. }\end{array}$ & $\begin{array}{l}\text { 3. Desenvolver ações cooperativas com fornecedores, vi- } \\
\text { sando à melhoria geral da cadeia produtiva. Por exemplo: } \\
\text { treinamentos conjuntos, certificação de qualidade, assis- } \\
\text { tência técnica, desenvolvimento conjunto de produtos e } \\
\text { investimentos em ativos compartilhados. } \\
\text { 4. Além de desenvolver ações cooperativas com os forne- } \\
\text { cedores diretos, há a preocupação em incluir o segundo } \\
\text { nível de fornecedores. }\end{array}$ \\
\hline Distribuidor & $\begin{array}{l}\text { 1. Obter as melhores margens e condições de } \\
\text { pagamento. } \\
\text { 2. Estabelecer maior colaboração e comuni- } \\
\text { cação com distribuidores, visando facilitar } \\
\text { o andamento das transações e fluxo de } \\
\text { mercadorias. }\end{array}$ & $\begin{array}{l}\text { 3. Desenvolver ações cooperativas com distribuidores, } \\
\text { visando produzir maior valor em conjunto. Por exemplo: } \\
\text { treinamentos conjuntos, certificação de qualidade, assis- } \\
\text { tência técnica, desenvolvimento conjunto de produtos e } \\
\text { investimentos em ativos compartilhados. }\end{array}$ \\
\hline Consumidor Final & $\begin{array}{l}\text { 1. A empresa percebe a importância do } \\
\text { consumidor final, mas não o inclui nas suas } \\
\text { estratégias. } \\
\text { 2. A empresa mantém um canal de comu- } \\
\text { nicação indireto com seus consumidores } \\
\text { finais, por meio de seus distribuidores e/ou } \\
\text { clientes. }\end{array}$ & $\begin{array}{l}\text { 3. A empresa mantém um canal aberto de comunicação } \\
\text { com seus consumidores finais, visando conhecer suas } \\
\text { necessidades. } \\
\text { 4. A empresa mantém um canal aberto de comunicação com } \\
\text { seus consumidores e inclui este conhecimento na formu- } \\
\text { lação de suas estratégias. }\end{array}$ \\
\hline
\end{tabular}

Fonte: Informações obtidas do questionário da pesquisa. 
Como apresentado no referencial teórico, nos setores industriais de alta tecnologia e até mesmo nos de tecnologia madura, como o da indústria automobilística, a inovação é produzida em rede e demanda por isto relacionamentos de longo prazo e mais sofisticados, nos quais o compartilhamento do conhecimento é praticado no dia-a-dia das empresas. Esta sofisticação dos relacionamentos visa à produção conjunta de conhecimento que realmente leve à produção de diferencial competitivo por meio da inovação.

\subsection{Relacionamento com distribuidores}

A análise das relações atuais com os distribuidores também apontou relacionamentos menos sofisticados, num total de 62,5\%, como mostrado no Figura 3. No entanto, este percentual é maior do que aquele aferido com os fornecedores. Além disto, é neste relacionamento que se percebe maior preocupação futura por parte dos respondentes, pois $82,8 \%$ pretendem torná-lo mais sofisticado no futuro. Pode-se considerar que as empresas revelaram uma postura atual mais próxima dos distribuidores, em comparação ao seu comportamento em relação aos fornecedores. Isto porque $37,5 \%$ dos respondentes indicaram estratégias de relacionamento mais sofisticadas com distribuidores, enquanto $26,7 \%$ optaram por este tipo de estratégia com relação aos fornecedores (Tabela 1).

A amostra revelou-se dividida no tocante ao relacionamento com os principais distribuidores, conforme as porcentagens abaixo:

- 34,4\% indicaram que a alternativa que melhor reflete a estratégia atual é: "Estabelecer maior colaboração e comunicação com distribuidores, visando a facilitar $o$ andamento das transações e o fluxo de mercadorias";

- 37,5\% optaram pela alternativa que representa uma estratégia mais sofisticada: "Desenvolver ações cooperativas com distribuidores visando a produzir maior valor em conjunto. Por exemplo: treinamentos conjuntos, certificação de qualidade, assistência técnica, desenvolvimento conjunto de produtos e investimentos em ativos compartilhados"; e

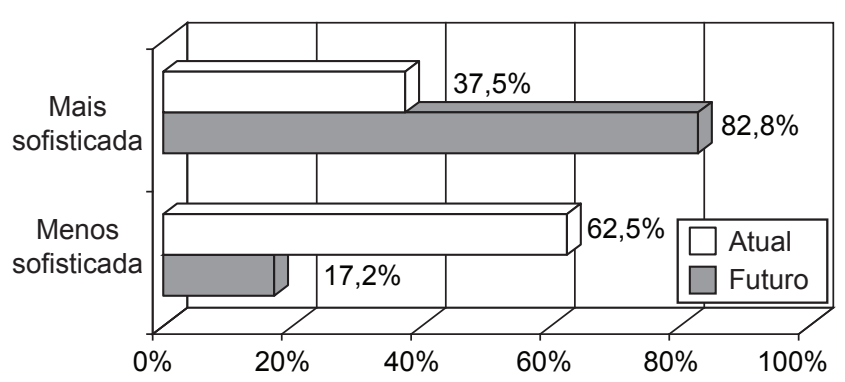

Figura 3. Estratégia de relacionamento com os distribuidores. Fonte: resultados da pesquisa.
- $28,1 \%$ afirmaram que sua estratégia atual está pautada em "Obter as melhores margens e condições de pagamento".

Quanto ao relacionamento futuro, uma maioria significativa das empresas consideradas $(82,8 \%)$ tem intenção de desenvolver relacionamentos mais próximos com o distribuidor, enquanto $66,7 \%$, com o fornecedor, representando uma tendência a uma intensa migração do nível menos sofisticado para o mais sofisticado. É interessante observar que as empresas encontram-se mais preocupadas com as relações estabelecidas com os distribuidores do que com os fornecedores. Este traço da amostra aponta para a importância de um aprofundamento deste tipo de estudo, com recortes em relação às características setoriais e tecnológicas dos respondentes. Pode-se estar diante de um conjunto de empresas marcadas por fortes relações de desenvolvimento junto a distribuidores, em que a sua performance estratégica é significativamente dependente dos distribuidores.

\subsection{Relacionamento com clientes}

Embora 50\% dos respondentes tenham optado por relações atuais mais sofisticadas com os clientes, há um percentual igual de 50\% das empresas que optaram por relações menos sofisticadas. Este resultado surpreende, devido à dinâmica do mercado atual que tem sido fortemente direcionado pelo foco no cliente. Novamente, características setoriais e tecnológicas poderiam explicar este tipo de comportamento.

Quanto à estratégia para daqui a cinco anos com relação aos clientes, a Figura 4 mostra que 78,4\% das empresas optaram pelo item "Desenvolver ações cooperativas com clientes, visando a produzir maior valor em conjunto. Por exemplo: treinamentos conjuntos, certificação de qualidade, assistência técnica, desenvolvimento conjunto de produtos e investimentos em ativos compartilhados".

\subsection{Relacionamento com consumidor final}

É importante ressaltar o comportamento das empresas participantes da pesquisa, em relação aos consumidores

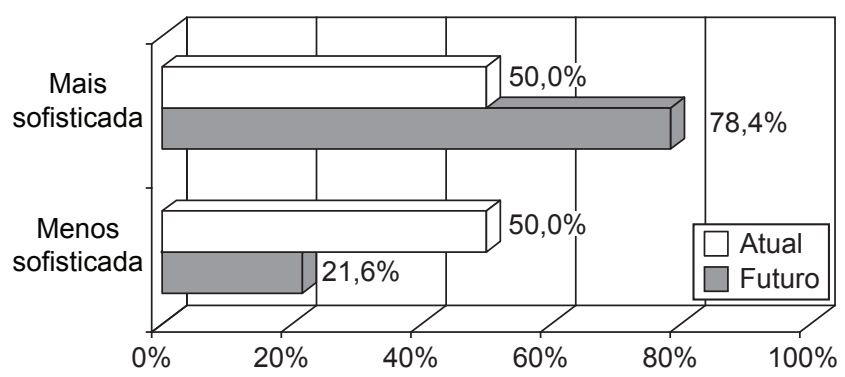

Figura 4. Estratégias de relacionamento com os clientes. Fonte: resultados da pesquisa. 
finais. Quando questionados sobre o tipo de relacionamento previsto para daqui a cinco anos, as respostas sinalizaram um recuo de relacionamentos mais sofisticados para menos sofisticados em 50\% da amostra (Figura 5). Esta aparente inconsistência, tanto do ponto de vista teórico quanto do prático, levou à hipótese de que, talvez, o distribuidor seja o elemento da cadeia que tenha o maior contato direto com o consumidor final e que, por causa disto, a estratégia de relacionamento mais sofisticada com o consumidor final fosse obtida por meio do distribuidor. No questionário, esta opção era representada pela alternativa: "A empresa mantém um canal de comunicação indireto com os consumidores finais por meio dos distribuidores".

Assim, com a finalidade de checar a hipótese levantada, os níveis de sofisticação da estratégia de relacionamento com o consumidor final foram reclassificados. Para tal, considerou-se a opção "Manter um canal de comunicação indireto com os consumidores finais por meio dos distribuidores" como estratégia mais sofisticada. Os resultados indicaram a tendência de elevação - de 34,1\% atuais para $63,9 \%$, no futuro - das estratégias mais sofisticadas, o que é consistente, seja da perspectiva teórica seja da prática, e fortalece a percepção da importância do distribuidor para a amostra pesquisada (Figura 6).

De uma maneira geral, pode-se comprovar pelos resultados da pesquisa que existe a intenção por parte das

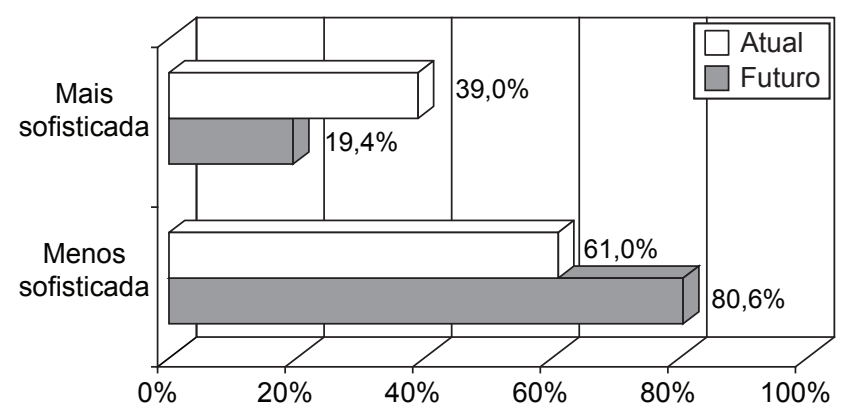

Figura 5. Estratégias de relacionamento com os consumidores finais. Fonte: resultados da pesquisa.

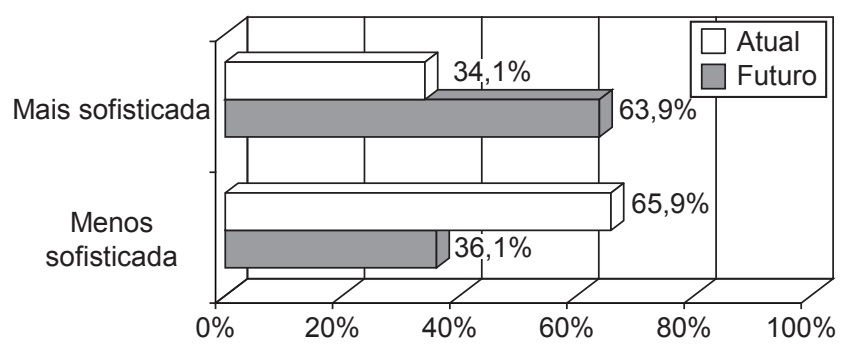

Figura 6. Estratégias de relacionamento com os consumidores finais (2). Fonte: resultados da pesquisa. empresas de migrar para os relacionamentos mais sofisticados para todos os elementos da cadeia, nos próximos cinco anos.

\subsection{Análise do relacionamento global na cadeia produtiva}

Estabelecendo-se uma gradação com relação à estratégia atual, percebe-se que, na amostra analisada, em um resumo dos resultados obtidos:

- $50 \%$ das empresas buscam relacionamentos mais próximos com os clientes;

- 37,5\% procuram estabelecer relações mais próximas com os distribuidores; e

- 26,7\% demonstram baixa preocupação em estabelecer vínculos maiores com os fornecedores.

Em síntese, percebeu-se que, atualmente, as estratégias estabelecidas ao longo da cadeia produtiva são pautadas por relações de mercado, isto é, a grande maioria destas relações são pouco sofisticadas. Elas não contemplam ações cooperativas conjuntas visando à melhoria geral da cadeia, como por exemplo, treinamentos conjuntos e desenvolvimento de ativos compartilhados. Destaca-se, no entanto, que o referencial teórico aponta estes elementos como sendo essenciais para o estabelecimento de uma estratégia de rede. As empresas demonstraram que ainda se encontram numa fase inicial do relacionamento com os parceiros, em comparação ao citado na literatura (Dyer e Nobeoka, 2000).

\subsection{Acompanhamento das relações na ca- deia produtiva}

A pesquisa partiu do pressuposto que uma estratégia bem estabelecida é aquela que se baseia em um acompanhamento realizado por meio de indicadores de resultado. Assim, no segundo bloco do questionário, os respondentes apontaram os indicadores utilizados para aferir o sucesso da estratégia adotada pela empresa junto aos componentes da cadeia produtiva. Esta pergunta permite avaliar quais são os principais indicadores utilizados na tomada de decisão das empresas, e se estes indicadores sinalizam para uma preocupação com a aprendizagem coletiva e o compartilhamento de conhecimento entre os participantes.

Apresentam-se, a seguir, os resultados da pesquisa relativos aos indicadores mais utilizados por cada elemento da cadeia. É preciso destacar que foi permitida a indicação de mais de uma opção nas questões abaixo.

\subsubsection{Fornecedores}

- $85,7 \%$ - o uso de indicadores objetivos de preço e qualidade dos insumos e serviços praticados pelos fornecedores em relação aos praticados pelos concorrentes dos fornecedores; 
- $62,9 \%$ - medidas qualitativas obtidas por contatos periódicos com os fornecedores, como visitas e inspeções periódicas;

- 45,7\% - número de contratos com fornecedores;

- 42,9\% - número de parcerias e alianças com fornecedores; e

- 34,3\% - número de programas e projetos que incluem os fornecedores nas iniciativas estratégicas da empresa.

Ressalta-se a parcela de apenas $34,3 \%$, que está preocupada em inserir os fornecedores nas iniciativas estratégicas da empresa.

\subsubsection{Distribuidores}

- $60,0 \%$ - medidas qualitativas obtidas por contatos periódicos com os distribuidores, como visitas e inspeções periódicas;

- 56,0\% - indicadores objetivos de preço e qualidade dos insumos e serviços praticados pelos distribuidores em relação aos praticados pelos concorrentes dos distribuidores;

- 44,0\% - pesquisas sistemáticas sobre o grau de satisfação dos distribuidores com sua empresa;

- 40,0\% - número de contratos com distribuidores; e

- 32,0\% - número de programas e projetos que incluem os distribuidores nas iniciativas estratégicas da empresa.

Ressalta-se a parcela de apenas 32,0\% preocupada em inserir os distribuidores nas iniciativas estratégicas da empresa.

\subsubsection{Clientes}

- 78,0\% - pesquisas sistemáticas sobre o grau de satisfação dos clientes com sua empresa;

- 61,0\% - medidas qualitativas obtidas por contatos periódicos com os clientes, como visitas e inspeções periódicas;

- 43,9\% - indicadores objetivos de preço e qualidade dos insumos e serviços praticados pelos clientes em relação aos praticados pelos concorrentes dos clientes;

- 41,5\% - número de contratos com clientes;

- 41,5\% - número de programas e projetos que incluem os clientes nas iniciativas estratégicas da empresa; e

- 41,5\% - número de parcerias e alianças com clientes.

Observa-se que os dois últimos indicadores utilizados para aferir o sucesso da estratégia junto aos clientes apontam para relações mais sofisticadas em relação aos clientes, porém eles são menos utilizados que o indicador relativo a preços e qualidade.

\subsubsection{Consumidores finais}

- 80,6\% - grau de satisfação dos consumidores finais com sua empresa; e

- 71,0\% - informações obtidas por contatos periódicos com os consumidores finais da sua empresa.

\subsection{Estratégia global da empresa vs. utilização de medidor de acompanhamento}

Apresenta-se, a seguir, uma comparação entre as sete orientações estratégicas consideradas mais importantes pelas empresas e o percentual de pesquisados que afirmaram utilizar algum medidor de acompanhamento. $\mathrm{O}$ objetivo desta comparação é observar se as estratégias tidas como importantes pelos respondentes são efetivamente acompanhadas, e em que posição apareceria a questão da cooperação e do compartilhamento do conhecimento. A primeira porcentagem apresentada no Tabela 2 se refere à importância dada à orientação estratégica e a segunda se refere ao uso desta orientação. Como demonstram os resultados, para várias estratégias, tidas como importantes, existe uma distância entre o grau da sua importância e o seu efetivo acompanhamento. Observou-se, por exemplo, que as orientações estratégicas que privilegiam a produção da inovação em rede não foram as mais citadas pelos respondentes. Ao contrário, as duas opções, que refletiriam relacionamentos em rede, estão entre as menos citadas.

Quanto aos indicadores utilizados para acompanhar as sete orientações estratégicas mais importantes, concluiuse que:

- Poucos indicadores são relacionados à performance da cadeia produtiva como unidade competitiva;

- A maioria dos indicadores é financeira;

- Foram priorizados os indicadores de preço e qualidade, indicadores de eficiência operacional, enfim, indicadores de relacionamentos pautados por relações de mercado e de curto prazo; e

- Somente um respondente apontou investimento em pesquisa e desenvolvimento como indicador de desempenho da estratégia de inovação (novos produtos/serviços, novos mercados, novos negócios, etc.).

Observa-se que os indicadores utilizados pelas empresas para avaliar o sucesso das estratégias atuais foram muito variados. Dos indicadores citados, alguns são relacionados ao número de parcerias e alianças, ações cooperativas e inclusão de sugestões de consumidores na estratégia empresarial. Apesar de não constituírem a maioria dos indicadores citados, considera-se que eles já sinalizam uma preocupação das empresas com os parceiros da cadeia produtiva.

Pôde-se concluir que as empresas participantes da pesquisa percebem hoje a cadeia produtiva como um flu- 
Tabela 2. Orientação estratégica vs. medidor de acompanhamento.

\begin{tabular}{|c|c|c|c|}
\hline & Estratégia Global da Empresa, em Ordem de Prioridade & Importância & Uso \\
\hline 1 & $\begin{array}{l}\text { Obter diferencial competitivo por meio da melhoria contínua (redução de custos ou aumento } \\
\text { de produtividade). }\end{array}$ & $69,6 \%$ & $72,1 \%$ \\
\hline 2 & Maximizar a riqueza dos acionistas a longo prazo (gerar valor). & $56,5 \%$ & $53,5 \%$ \\
\hline \multirow[t]{2}{*}{3} & Criar/desenvolver cultura de inovação e empreendedorismo. & $50,0 \%$ & $27,9 \%$ \\
\hline & Desenvolver pessoas e competências (liderança). & $50,0 \%$ & $37,2 \%$ \\
\hline \multirow[t]{2}{*}{4} & $\begin{array}{l}\text { Antecipar-se às expectativas das partes interessadas (acionistas, clientes, fornecedores, } \\
\text { sociedade, etc.) }\end{array}$ & $45,7 \%$ & $14,0 \%$ \\
\hline & Aumentar a participação de mercado. & $45,7 \%$ & $60,5 \%$ \\
\hline 5 & $\begin{array}{l}\text { Diversificar as fontes de receita da empresa (novos produtos/serviços, novos mercados, } \\
\text { novos negócios, etc.). }\end{array}$ & $43,5 \%$ & $32,6 \%$ \\
\hline \multirow[t]{2}{*}{6} & $\begin{array}{l}\text { Desenvolver e consolidar parcerias/alianças/contratos de longo prazo com fornecedores, } \\
\text { distribuidores, clientes e consumidores finais. }\end{array}$ & $39,1 \%$ & $14,0 \%$ \\
\hline & $\begin{array}{l}\text { Desenvolver cultura de desenvolvimento sustentável (suprir necessidades do presente, sem } \\
\text { comprometer o futuro). }\end{array}$ & $39,1 \%$ & $20,9 \%$ \\
\hline \multirow[t]{2}{*}{7} & $\begin{array}{l}\text { Obter diferencial competitivo por meio do desenvolvimento sustentável (satisfazer necessida- } \\
\text { des do presente, sem comprometer o futuro). }\end{array}$ & $37,0 \%$ & $20,9 \%$ \\
\hline & $\begin{array}{l}\text { Desenvolver/gerenciar conhecimento sobre processos, materiais, produtos, serviços, tecnolo- } \\
\text { gias, mercados, etc. }\end{array}$ & $37,0 \%$ & $23,3 \%$ \\
\hline
\end{tabular}

Fonte: resultados da pesquisa.

xo de produtos e serviços, cujos valores gerados pouco dependem do relacionamento estabelecido entre seus componentes. Entretanto, foi mostrada a intenção destas mesmas empresas para uma mudança de comportamento, podendo a rede se transformar num sistema cuja dinâmica e potencial sejam capazes de agregar valor aos seus produtos e serviços. Conforme descrito na literatura, este estágio só é atingido pelo compartilhamento do conhecimento e de fortes relações de confiança, em que a cooperação é mais importante do que a competição, nos moldes das cadeias produtivas do setor automobilístico, pesquisadas por Dyer e Nabeoka (2000).

\section{Breve comparação dos resultados da pesquisa com a experiência da Toyota}

São feitas, neste item, algumas considerações sobre os resultados da pesquisa sobre o relacionamento na Cadeia Produtiva no Brasil e o caso Toyota, analisado em profundidade pelos autores Dyer e Nobeoka (2000) e citado na literatura como exemplo de sucesso da sociedade em rede. Para os autores, a indústria automobilística proporciona casos interessantes para a análise de aprendizagem interorganizacional, uma vez que ela trabalha em rede. Segundo eles, aproximadamente $70 \%$ do valor de um veículo é produzido pelos fornecedores de peças e sistemas automobilísticos. Em estudo anterior, Dyer (1996) mostrou que a indústria automobilística japonesa é mais efetiva em trabalhar com redes que a indústria automobilística americana, tendo como destaque o produtor japo- nês de automóvel Toyota. Os autores decidiram estudar o caso Toyota pelos seguintes motivos: a Toyota é amplamente reconhecida como líder no aprendizado e melhoria contínua; ela é a empresa japonesa, regularmente, eleita por executivos japoneses como a mais bem gerenciada e a empresa japonesa mais respeitada; a rede Toyota é altamente efetiva em compartilhar conhecimento entre as empresas da rede.

Com o objetivo de verificar quais eram as rotinas de compartilhamento de conhecimento tácito que eram institucionalizadas na rede Toyota e como a Toyota resolve os dilemas de compartilhamento de conhecimento, os autores entrevistaram os gerentes gerais de compras do Japão e dos EUA. O objetivo destas entrevistas era identificar as unidades ou divisões dentro da empresa que interagem com os fornecedores e que estão envolvidas com as atividades de desenvolvimento dos fornecedores. Dyer e Nobeoka (2000) ressaltam que este tipo de organização é difícil de ser atingida e em parte explica a razão pela qual o Sistema Toyota de Produção continua sendo uma fonte de vantagem competitiva.

A Toyota elegeu três processos internos como sendo prioritários para o compartilhamento do conhecimento. A estratégia foi criar, inicialmente, ligações tênues e não ameaçadoras entre os parceiros e migrar lentamente para relacionamentos sólidos e confiáveis. Os processos priorizados foram: o estímulo à associação de fornecedores, a criação de grupos de consultoria e a formação de equipes de aprendizado voluntário. 


\subsection{0 estímulo à associação de fornecedo- res}

Nos EUA, a Toyota reuniu os seus fornecedores, criando uma associação denominada Bluegrass Automotive Manufacturers Association (BAMA), cujo objetivo era criar um fórum de compartilhamento de informações e conhecimento. Apesar do caráter voluntário da associação, os fornecedores se interessaram em participar, pois identificaram vantagens em ser associado. As reuniões propiciavam aos participantes o compartilhamento do conhecimento em áreas como: planos de produção, políticas, tendências do mercado, etc., dentro da rede de fornecedores. A associação se encarregou de várias atividades como treinamento básico para engenheiros e técnicos, visitas às fábricas, divulgação das melhores práticas de produção dentro e fora do setor automobilístico, gestão da qualidade, etc.

\subsection{A criação de grupos de consultoria e de solução de problemas}

A Toyota já era conhecida no Japão pelos seus grupos de consultoria e solução de problemas. Esta idéia foi ampliada para os EUA na década de 90, com o objetivo de adquirir, armazenar e compartilhar conhecimentos valiosos sobre a produção. Os grupos são geralmente formados por executivos e consultores seniores, além de outros profissionais jovens, em busca de crescimento rápido. Os participantes destes grupos são obrigados a compartilhar o conhecimento, os resultados de seus projetos com os outros fornecedores. Esta prática é considerada estratégica pela empresa, pois aumenta exponencialmente as possibilidades de um fornecedor conseguir reproduzir com sucesso o know how adquirido por outros fornecedores. Dyer e Nobeoka (2000) ressaltam que, muitas vezes, é preciso uma mudança cultural e organizacional nas empresas parceiras, para que bons resultados sejam atingidos.

\subsection{A formação de equipes de aprendizado voluntário}

As equipes de aprendizado voluntário (Jiskuken) são consideradas mecanismos modernos de compartilhamento do conhecimento. Seus membros aprendem em grupo, explorando novas aplicações e idéias que valham a pena para a Toyota e sua rede de fornecedores. Dyer e Nobeoka (2000) chamam a atenção para o fato de que as transferências de conhecimento tácito pelas equipes de aprendizado voluntário são eficazes porque implicam no aprendizado dentro do contexto apropriado. Os resultados alcançados podem atingir redução de custos da ordem de $30 \%$, comprovados pelos participantes da rede.

\subsection{Principais conclusões do caso Toyota}

As principais conclusões encontradas pelos autores em relação à rede Toyota foram:
- Os fornecedores da Toyota são motivados a participar do compartilhamento aberto (para toda a rede) do conhecimento porque rapidamente tomam consciência de que participar do processo de aprendizagem coletiva é amplamente superior a uma tentativa isolada;

- Há um número de processos (rotinas) de compartilhamento de conhecimento no nível da rede que ajuda a criar uma forte identidade para a rede;

- Há o estabelecimento de regras para a rede que impedem que os fornecedores tenham acesso aos conhecimentos da Toyota sem que eles, explicitamente, concordem em abrir seu conhecimento para todos da rede. O descumprimento destas regras leva a sanções comerciais por parte da Toyota;

- As conexões da rede são apropriadas para a difusão eficiente (rápida e fácil) do conhecimento tácito entre todos os elementos da rede;

- Ao compartilhar seus conhecimentos com seus fornecedores, a Toyota ajudou a melhorar significativamente o desempenho deles e, em paralelo, o seu desempenho próprio; e

- A experiência da Toyota sugere que as vantagens competitivas podem ser criadas e sustentadas por meio dos processos eficazes de compartilhamento de conhecimento em uma rede.

Uma rápida comparação do caso Toyota com os resultados da pesquisa com 46 empresas brasileiras sinaliza para comportamentos bastante diferenciados. É possível verificar um atraso deste grupo de empresas em relação ao exemplo japonês e à literatura sobre as características da sociedade em rede. Não se pode deixar de salientar que as relações na cadeia produtiva variam de acordo com o setor empresarial, nível de sofisticação das tecnologias utilizadas, se as empresas se consideram inovadoras, seguidoras rápidas, seguidoras ou tradicionais (Vasconcelos e Ferreira, 2002). Este comportamento empresarial já foi estudado por outros autores, que têm citado a Empresa Brasileira de Aeronáutica - Embraer - como exemplo brasileiro de empresa de sucesso na gestão da cadeia produtiva de alta sofisticação tecnológica (Terra, 2000). Este exemplo demonstra que os resultados apresentados neste artigo devem ser analisados com cautela e não devem ser generalizados para outras empresas ou setores industriais.

\section{Conclusões}

O presente artigo teve por objetivo discutir a estratégia de relacionamento entre os membros da cadeia produtiva no Brasil, com foco na aprendizagem e no compartilhamento do conhecimento, em contextos marcados pela inovação e pela formação de redes. São pressupostos do 
artigo que as redes se tornaram importantes variáveis estratégicas para as empresas e têm afetado toda a estrutura industrial e a forma de competição. Para dar suporte à discussão sobre o tema, foram apresentados os conceitos centrais disponíveis na literatura, como a importância do fluxo de conhecimentos, do aprendizado e da inovação na sociedade em rede, e os impactos destes conceitos no pensamento e na formulação estratégica. Observa-se, hoje, que parte significativa do valor dos produtos das empresas é produzida nestas redes e não mais isoladamente por uma única empresa, como mostrado no caso Toyota.

Foram apresentados os resultados de uma pesquisa sobre cadeias produtivas no Brasil em que foram analisados os relacionamentos das empresas com fornecedores, distribuidores, clientes e consumidores finais. A principal função da análise foi a de levantar pontos para reflexão sobre o comportamento destas empresas. Pôde-se concluir que as empresas analisadas percebem hoje a cadeia produtiva como fluxos de produtos e serviços, cujos valores gerados pouco dependem do relacionamento estabelecido entre seus componentes. Um exemplo deste relacionamento está no tipo de resposta obtida, isto é, quando questionados sobre as relações atuais da empresa com os principais fornecedores, a amostra concentrou-se na alternativa:

"Obter os melhores preços, qualidade e condições de fornecimento."

Entretanto, foi mostrada a intenção destas mesmas empresas para uma mudança de comportamento, vindo no futuro a desenvolver ações cooperativas com fornecedores e distribuidores, melhorando a cadeia produtiva e produzindo mais valor em conjunto. Exemplo: com relação à estratégia futura de relacionamento com os fornecedores, a maioria dos respondentes selecionou a alternativa abaixo, que sinaliza a intenção de se adotar uma estratégia mais sofisticada, no futuro.

"Desenvolver ações cooperativas com fornecedores, visando à melhoria geral da cadeia produtiva, por meio de treinamentos conjuntos, obtenção de certificação de qualidade, assistência técnica, desenvolvi- mento conjunto de produtos e investimentos em ativos compartilhados."

Esta postura reflete que, embora a estratégia atual adotada pelas empresas não se encontre em consonância com a teoria descrita neste artigo, a qual sinaliza que na "sociedade do conhecimento" as empresas deveriam buscar relacionamentos em rede, já existe a percepção da importância deste tipo de relacionamento. Foi verificado que as empresas encontram-se compelidas a caminhar para este estágio. Assim, a rede poderá se transformar num sistema cuja dinâmica e potencial sejam capazes de agregar valor aos seus produtos e serviços, pelo compartilhamento do conhecimento e de fortes relações de confiança, em que a cooperação é mais importante do que a competição, seguindo o modelo de cadeias produtivas do setor automobilístico (Dyer e Nobeoka, 2000).

O exemplo da rede liderada pela Toyota mostra que quanto mais cooperativo é o relacionamento entre os elementos que compõem a cadeia produtiva maior é o compartilhamento do conhecimento, o que contribui para a competitividade da empresa. A idéia, marcadamente presente ao longo do artigo, é de que a criação, compartilhamento e apropriação de valor implicam que toda empresa deve ser considerada no contexto da sua cadeia produtiva. Conforme os vários autores citados, a geração compartilhada de conhecimento vem adquirindo grande importância, sendo incluída na estratégia da organização e na busca do fortalecimento do conhecimento coletivo.

Entre os pontos de reflexão que este artigo propõe, ressalta-se o desafio, para a comunidade empresarial e acadêmica, de difundir a consciência no Brasil de que participar do processo de aprendizagem coletiva é amplamente superior a uma tentativa isolada. Questiona-se se o país está preparado para competir numa economia em que a estratégia está focada na importância dada ao compartilhamento do conhecimento, na aprendizagem, na inovação e nas relações de confiança necessárias à sociedade em rede, que substitui antigos comportamentos em que as empresas competiam unicamente por lucros, umas contra as outras, em um mercado impessoal.

\section{Referências Bibliográficas}

DYER, J. Specialized Supplier Networks as a Source of Competitive Advantage: Evidence from the Auto Industry. Strategic Management Journal, v. 17, n. 4, p. 271-291, 1996.

DYER, J.; NOBEOKA, K. Creating and managing a highperformance knowledge-sharing network: the Toyota case. Strategic Management Journal, v. 21, n. 3, p. 345-367, March, 2000.
GULATI, R.; NOHRIA, N.; ZAHEER, A. Strategic Networks. Strategic Management Journal, v. 21, n. 3, p. 203-215. March, 2000.

KALE, P.; SINGH, H.; PERLMUTTER, H. Learning and protection of proprietary assets in strategic alliances: building relational capital. Strategic Management Journal, v. 21, n. 3, p. 217-237, March, 2000. 
LEONARD-BARTON, D. Nascentes do saber: criando e sustentando as fontes de inovação. Rio de Janeiro: Fundação Getúlio Vargas, 1998.

LUNDVALL, B. National systems of innovations: towards a theory of innovation and interactive learning. London: Pinter Publishers, 1992.

SCHUMPETER, J. Capitalismo, Socialismo e Democracia. Rio de Janeiro: Jorge Zahar Editor, 1984.

SINGH, K.; MITCHELL, W. Precarious Collaboration: Business Survival After Partners Shut Down or Form New Partnerships. Strategic Management Journal, v. 17, n. 9, p. 99-115, 1996.

TERRA, J. C. Gestão do Conhecimento - O grande desafio empresarial: uma abordagem baseada no aprendizado e na criatividade. São Paulo: Negócio Editora, 2000 .
VASCONCELOS, M. C. Cooperação Universidade Empresa na Pós Graduação: Contribuição para a Aprendizagem, a Gestão do Conhecimento e a Inovação na Indústria Mineira. 2000. 257f. Tese (Doutorado em Ciência da Informação) - Escola de Ciência da Informação, Universidade Federal de Minas Gerais, Belo Horizonte, 2000.

VASCONCELOS, M. C.; FERREIRA,. O Desafio da Gestão do Conhecimento Tecnológico nas Empresas. In: XX Simpósio de Gestão da Inovação Tecnológica. Anais..., Salvador, 2002.

YOSHINO, M.; RANGAN, U S. Alianças estratégicas: uma abordagem empresarial à globalização. São Paulo: Makron Books, 1996.

\title{
STRATEGY OF RELATIONS AMONG THE MEMBERS OF THE PRODUCTIVE CHAIN IN BRAZIL: REFLECTIONS ON THE THEME
}

\begin{abstract}
The growing number of alliances among organizations has led to the formation of real networks, forming the socalled Network Society. It is evident, today, that most of the value of these companies' products is produced within these networks rather than by a single company. This article discusses knowledge sharing in contexts marked by innovation and by the creation of networks, and presents a survey on productive chains in Brazil involving 46 companies. In this context, we analyze these companies' relations with suppliers, distributors, customers and consumers. Our findings are compared with the successful case of a productive chain of the automotive sector, indicating that most companies still have a long way to go in terms of improvements in order to enter into the framework of the Network Society.
\end{abstract}

Keywords: strategy, knowledge society, network society, supply chain, learning. 